\title{
Experimental device for measuring the dynamic properties of diaphragm motors
}

\author{
Kamil Fojtášek ${ }^{1, a}$, Lukáš Dvořák $^{1}$ and Jan Mejzlík ${ }^{1}$ \\ ${ }^{1}$ VŠB-Technical University of Ostrava, Faculty of Mechanical Engineering, Department of Hydrodynamics and \\ Hydraulic Equipment, 17. listopadu 15/2172, Ostrava 70833, Czech Republic
}

\begin{abstract}
The subject of this paper is to design and description of the experimental device for the determination dynamic properties of diaphragm pneumatic motors. These motors are structurally quite different from conventional pneumatic linear cylinders. The working fluid is typically compressed air, the piston of motor is replaced by an elastic part and during the working cycle there is a contact of two elastic environments. In the manufacturers catalogs of these motors are not given any working characteristics. Description of the dynamic behavior of diaphragm motor will be used for verification of mathematical models.
\end{abstract}

\section{Introduction}

The object of this article is the design of the experimental device to determine dynamic properties of pneumatic motors. Design of this equipment with a verification of its functionality was a part of the solution in the magister thesis. Pneumatic systems are used in many industrial applications. They are part of automated production lines, plays an irreplaceable role in the handling of materials or products. Bearer of energy and information (control signal) is compressed air. This fact brings considerable advantages in using of these systems. Internal overpressure prevents to get dirt (contaminants) into system, itself clean of working medium offers the use of these systems in the food industry, or pharmaceutical industry. Compressibility of air allows overloading of pneumatic motors without consequences for their damage, absence of electrical wiring allows work in explosive environments.

Pneumatic mechanisms usually work with a maximum pressure $1 \mathrm{MPa}$. Common working pressure is $0,6 M P a$, to this pressure is also adapted all elements of the pneumatic circuit. This relatively low pressure, together with the previously mentioned compressibility of the working medium, limits the maximum force generated by a pneumatic motors. Common mass produced linear motor generates a maximum force $30000 \mathrm{~N}$ (with pressure 0,6 MPa) and the cylinder diameter $250 \mathrm{~mm}$. Pneumatic motors with larger diameters are generally not produced. As a possible alternative we can use a pneumatic linear motors with special construction. One of the special construction are pneumatic motors with elastic working elements. In these motors is the working element (piston), or another part of motor, replacing a flexible (usually rubber) part. When working, therefore to comes into contact of two flexible environment. Compressed air on one side and a flexible rubber part on the other. A group of these motors include air bellows and diaphragm motors. Generally these engines are classified as low-stroke. Stroke of motors is limited by extend and deformation of the flexible part. Air bellows motors work practically without friction. They are made in the basic design up to diameter $400 \mathrm{~mm}$, and can be implemented force to $70000 \mathrm{~N}$. In this design, allow the use of up to $20^{\circ}$ tilting [1]. Pneumatic diaphragm motors Fig. 1 are used as a linear single acting or double-acting low-stroke motors, especially in the regulatory systems. The elastic (rubber) membrane is fixed to the edge of the motor housing and in the middle on both sides by metal rings, to which is attached the piston rod. When working causes to movement of the diaphragm (and its deformation) in the motor housing. Using diaphragm motors can be realized force to $30000 \mathrm{~N}$.

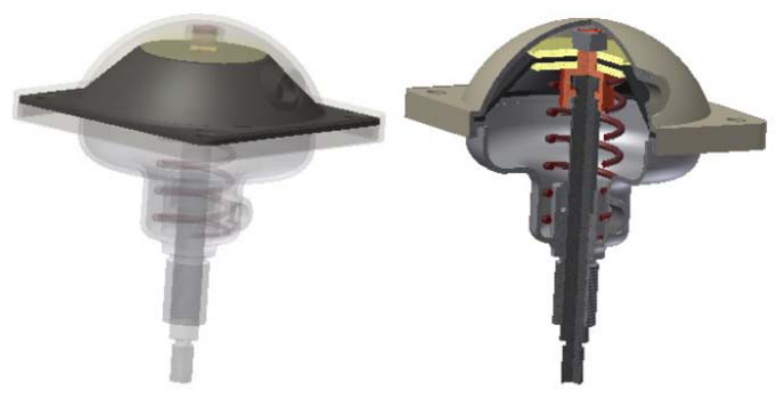

Fig. 1. Pneumatic diaphragm motor

At a the theoretical determination of the diaphragm motor workforce, it is necessary to proceed from an effective membrane area (which is changed during the stroke). A detailed description of the calculation of the effective area was made in the post [2]. A group of of pneumatic motors with an elastic working element includes fluid muscles. But they have the theoretical force only about

\footnotetext{
a Corresponding author: kamil.fojtasek@vsb.cz
} 
$10000 \mathrm{~N}$. However, looking at the above types of motors, it is evident that among themselves greatly differ.

\section{Experimental device}

When designing experimental equipment must be taken into account constructional and functional differences between different pneumatic motors. For a description of dynamic properties is considered to conventional linear motors, air bellows, diaphragm motors and fluid muscles. Measuring device must be universal. In the past, was in the laboratory of pneumatic mechanisms assembled device for the measurement of static characteristics of these engines [3]. On this measurement device it was possible to measure only static characteristics, at higher load occurred to weightlifting of guide rods, and small overall stiffness of the device not to guarantee accurate results of the measured values. Load was realized by combining mass load and pneumatic motor. Pneumatic part of the load was very difficult to regulate and device at higher pressures has not been able to work with constant load. In view of the fact that the air bellows and diaphragm motors have a higher force effects than conventional pneumatic motors. It is necessary for the measurement of static and primarily dynamic characteristics to ensure adequate load with sufficient stiffness and fast accurate regulation.

At the final design were compared two options of experimental device. Screwed vertical variation Fig.2 (left), and welded horizontal variant Fig.2 (right).

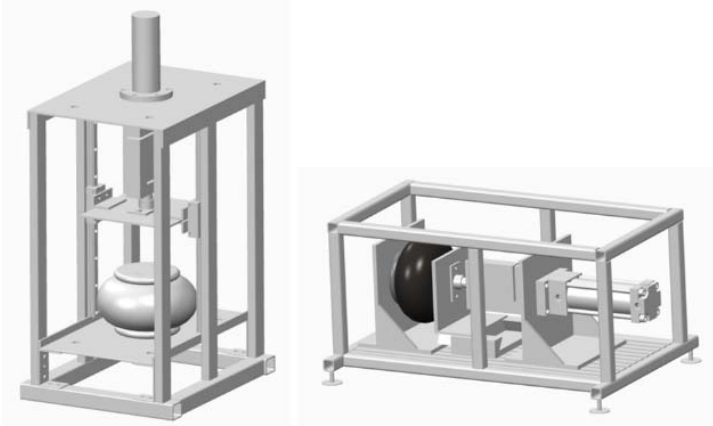

Fig. 2. Variants of solution experimental device, vertical variation (left), horizontal variation (right)

The first construction design solutions of test device is considered as screwed or possibly welded construction, the main force effects on testing pneumatic motor will acting in the vertical axis. The main frame is made of steel tubes of rectangular profile. On the upper frame part is mounting a plate, on which is mounted by screws hydraulic cylinder as the main generator of force effects on the test motors. On the bottom plate is mounted tested pneumatic motor, which is from the upper side fixed to the central plate. The central plate is fixed to the two slideways, which ensure smooth movement and reduce the deflection caused by the load. To the central plate is mounting from above the load cell, for measuring the force effect and its mounting to piston rod of hydraulic cylinder. The lower plate is variably adjustable to a several heights according to the type of tested motor. For larger air bellows motors is more advantageous location in the lower position and saved space serves for motor for installation and measurement equipment. In the case if is tested diaphragm motor which has most of the construction parts under mounting plate, this plate is fixed in the upper position. Fluid muscles can be suspended on the upper part of the frame. The second variant has a welded frame construction which has in a bottom plate opposite $\mathrm{T}$ shaped channel. This allows quick and easy mounting of working parts. In this case, there are mounted three parts on which there are mounted pneumatic motors and a center plate. The elements are attached so that the main force effects acting in the horizontal plane. This may result in deflection of the outer element which are mounted only on one side (by the influence of gravitational forces). The whole assembly is welded which not allows the variability of test motors. The whole device is undetachable except the parts placed on the grooved plate. This fact for any change of the workplace generates a few problems from dimensional to weight. Comparison of the above was carried out using the value analysis where, as evaluation criteria were e.g. weight, method of production, distribution of mass or price. Based on this comparison, for the realization was selected a vertical variation of the experimental device in screwed design. After the dimensional the proposal of the chosen solution was the construction checked on strength-static loads in software ANSYS. The control of tension and deformation was focused on the top and bottom plate on which are mounted the test and load motors.

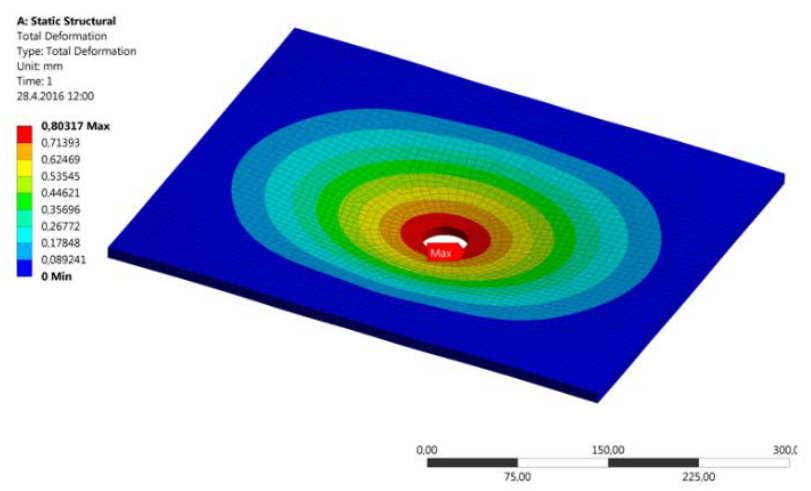

Fig. 3. Deformation of top plate

The analysis was set to for the load $20000 \mathrm{~N}$ acting in the axis of device where also acting the hydraulic motor. Deformation at the most critical point not exceed the value $1 \mathrm{~mm}$ Fig.3. which can be considered as sufficient and for the measurement these minimum values will have no relevant influence [4].

That the equipment can be considered fully operational, it was necessary to ensure that during measurement avoid friction in places where a central plate is fitted with a motion sensor. This is achieved by using a linear ball guide. As already mentioned, the original measuring device not ensure sufficient stiffness of the load (pneumatic) motor which in measurement replaces the mass load. As a source of static and dynamic load will be used the hydraulic motor with a small stroke. For the conditions in the laboratory and the elements that are available, it was selected maximum working load 
$20000 \mathrm{~N}$ and working pressure of approximately $10 \mathrm{MPa}$. At this load was dimensioned hydraulic motor with a piston diameter $50 \mathrm{~mm}$. With regard to the measured pneumatic motors with elastic working elements which can be described as low-stroke, it was selected stroke of hydraulic motor $80 \mathrm{~mm}$. Stroke and loading force of the hydraulic motor can be changed at any time by selecting a different type of motor. The speed of movement of the piston has been pre-selected to $0,1 \mathrm{~m} \cdot \mathrm{s}^{-1}$ and for this parameters were designed compact hydraulic power unit with small space requirements.

\section{Experimental measurements}

Functionality of designed experimental device was tested for measuring static characteristics of the diaphragm motor. When measuring static characteristics, we based on the fact that the tested motor is loaded with mass load. This load have a constant value and measured variables are force $F$, which affected by mass load on the measured motor, depending on the change of stroke motor $x$. Pressure $p$ in measured motor which must be also constant. These measurements are repeated for the other values of mass load and a series of test pneumatic motors.

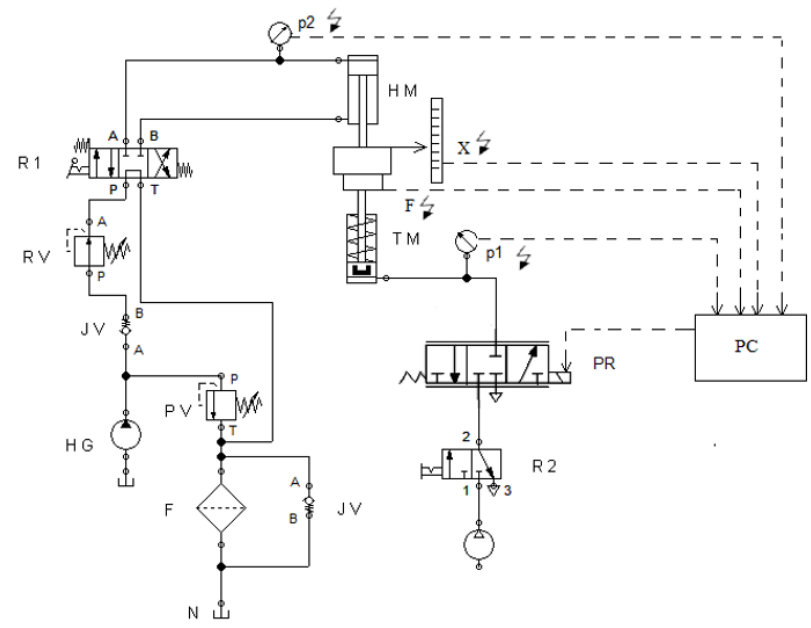

Fig. 4. Diagram of hydraulic and pneumatic circuit

On diagram Fig.4. the test circuit is divided into two parts - pneumatic and hydraulic. The pneumatic part is connected to the central supply of compressed air with pressure 0,6 $M P a$ and through a valve $R 2$ is controlled air bellows or diaphragm test motor TM. To ensure a constant pressure in the pneumatic motor is in circuit proportional pressure regulator $P R$ with bidirectional flow. Because the both pneumatic actuators are singleacting is necessary to ensure discharge of air during reverse movement. The hydraulic circuit is ensured by a hydraulic unit $H G$ which supplies pressure fluid on the maximum pressure $12 \mathrm{MPa}$. This value is limiting by safety valve $P V$. For correct measurements it must be load force from the hydraulic motor for fractional measurement constant. This condition ensures a pressure reducing valve $R V$. Hydraulic motor $H M$ is double acting and its control is ensured by valve $4 / 3$ actuated by button R1. To measure static and dynamic characteristics of motors with elastics working elements was created a control program in Matlab Simulik. With this program you can acquire and evaluate the measured variables, concretely force $F$, piston rod stroke of tested motor $x$ and pressure in tested motor $p_{l}$. As described above, when measuring the static characteristics is kept a constant pressure in the measured motor. This pressure is controlled by a proportional pressure regulator and its value is set to as a constant progression in the program. For measuring the dynamic characteristics is possible in this program enter any course of the signal and regulate the pressure in the measured motor.

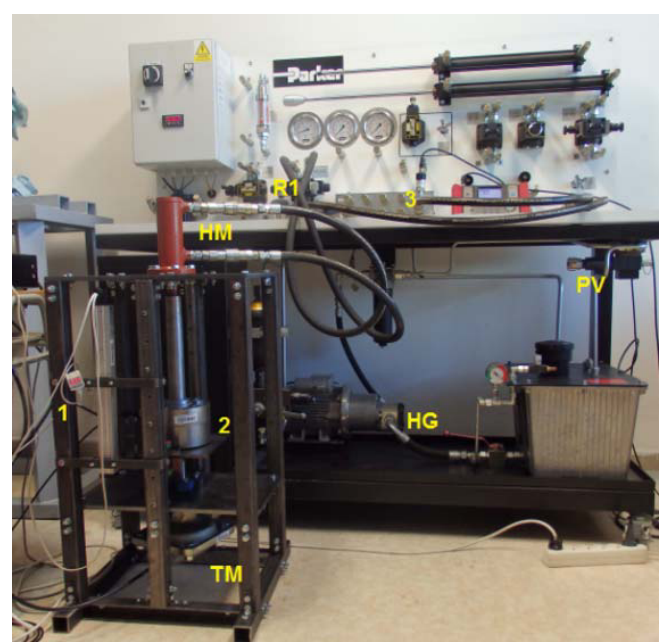

Fig. 5. Description of the experimental device

R1 - directional valve, HM - hydraulic motor, $H G$ hydraulic pump, $P V$-safety valve, TM -tested motor, 1 pressure $p_{1}$ sensor, 2 -force sensor, 3- pressure $p_{2}$ sensor

The measurement process is described by Fig.5. and Fig.6. In this measurement was used in the hydraulic part an educational stand Parker. For the measurement of static characteristics is constant pressure $p_{l}$ in tested motor TM. This is achieved by setting the desired pressure in the control program which sends through a measurement card 5 signal to proportional control valve $P R$. In hydraulic circuit is on the safety valve $P V$ set up required pressure value $p_{2}$ and in interaction of hydraulic motor $H M$ and tested motor $T M$ we find force effects using by sensor 2 and the displacement of piston rod by sensor 4 . At the beginning of measurement is the pressure $p_{2}$ on safety valve $P V$ set to the minimal value and progressively this value increases. This leads to ejection of piston rod $H M$. This way you can achieve a range of values with constant load for which you can save an individual measurements at different stroke of measuring motor.

The duration of one measurement is 30 seconds, the values used for the creation of characteristics are recorded only the last 10 seconds of measurement due to stabilization at a constant position. When measuring the dynamic characteristics the circuit is a same. In the control program sets the pressure change in the measured or hydraulic motor. Duration of the measuring is selected according to the character of load.

Sensor values of air pressure, force and stroke are through the measuring card sent to $P C$, where they are processed in the form of static and dynamic characteristics. 


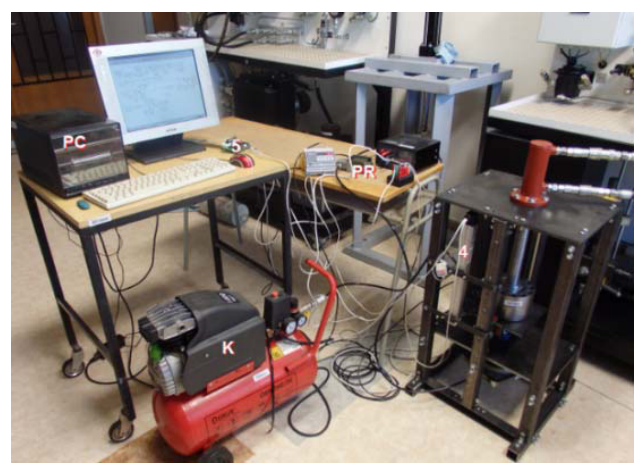

Fig. 6. Description of the experimental device

$P C$ - control computer, $K$-compressor, $P R$ - proportional pressure regulator, 4 -position sensor, 5 -measuring card

In view of the fact that in manufacturer catalog of diaphragm motors does not list any output characteristics, the results of the test measurements were compared with the results of previous measurements (on the previous experimental stand) [5]. From the comparison Fig.7. is obvious that the measured values are lower about $500 \mathrm{~N}$. At the maximum stroke of the motor there is no significant decrease in force. It is also evident that even at higher pressures it was possible to measure the force in full stroke of motor.

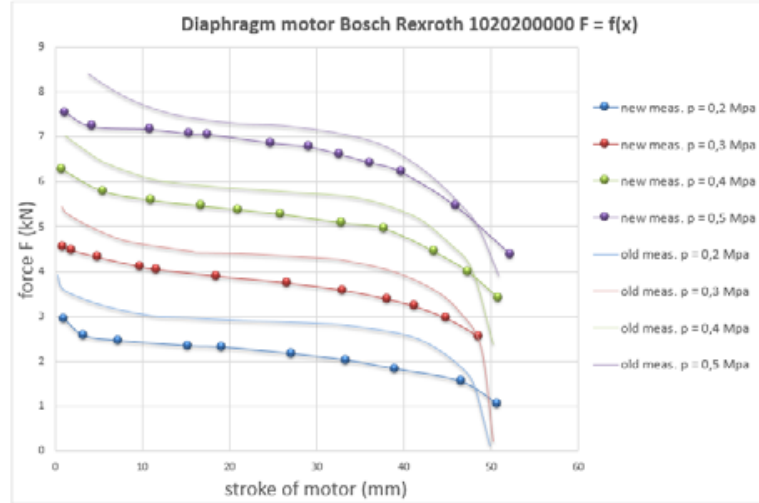

Fig. 7. Static characteristics - the force depending on the stroke

In the case of dynamic characteristics are variables changing with a time and the it is necessary to regulate (control) the pressure in the measured motor or resize the mass load, depending on the type of measurement. The involvement would be similar to Fig.4. In the case of pressure control in the measured motor $T M$ would be used proportional valve $P R$. In the case of regulation on a mass load would be reducing valve $R V$ replaced by proportionally controlled reducing valve.

For test measurement of dynamic characteristics has been created a control signal which controlled the pressure in the measured motor. The duration of measurement was 14 seconds, when in third second was abruptly increased pressure $p_{l}$ in measured motor. Time of pressure increase from the minimum value to the maximum was $0,1 \mathrm{~s}$. At the time of $10 \mathrm{~s}$ was again abruptly pressure drop to a minimum value. Progression of pressure $p_{l}$, force $F$ and stroke $x$ depending on time $t$ from software Matalb Simulink are shown in Fig.8. From progression of force is evident relatively significant oscillation about a mean value, this problem could be solved by using force sensor with a lower working range. To stabilizing of force at the end of stroke occurs after less than $1 \mathrm{~s}$, which I consider as sufficient and selected mass load can be used to measure the dynamic characteristics of pneumatic motors. Speed of extension and retraction of both motors can be controlled by throttle valves.

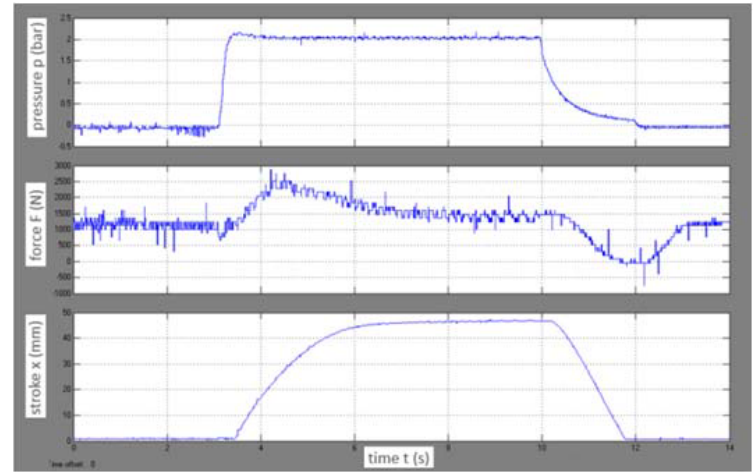

Fig. 8. Progression of pressure, force and stroke of diaphragm motor in dynamic measurement

\section{Conclusion}

In this paper was described proposal of experimental device for measuring the dynamic properties of pneumatic motors. It was chosen universal vertical design experimental device with the possibility to measure a different types of pneumatic motors. As a mass load was used hydraulic motor which is sufficiently tough and its load can be continuously controlled. The function of the proposed device was tested at measuring of diaphragm motor. In the future the equipment will be used to determine the dynamic behavior diaphragm motors. The measured data will serve for verification and verification of mathematical models.

\section{Acknowledgements}

This work was supported by the project SP2015/95 of VŠB Technical University of Ostrava.

\section{References}

1- K. Fojtášek, J. Kopáček, L. Dvořák, Pneumatické motory s elastickými pracovními členy, Sbornik př́spěvků 30. Setkání kateder mechaniky tekutin a termomechaniky, p.37 (2011)

2- K. Fojtášek, J. Kopáček, Pneumatic motors with elastic working elements and their mathematical modeling, Journal of the 21. International conference on hydraulic and pneumatic, p.171 (2011)

3- K. Fojtášek, L. Dvořák, J. Kopáček, Měření statických charakteristik pneumatických motorů $\mathrm{s}$ elastickými pracovními členy, Hydraulika a pneumatika, 1-2, p.9, (2012)

4- J. Mejzlík, Zkušební zařízení pneumatických motorů, Magister Thesis, VŠB-TU Ostrava, (2016)

5- K. Fojtášek, L. Dvořák, Mathematical Modeling of Diaphragm Pneumatic Motors, in EPJ Web of Conferences 67, 02028 (2014) 